\title{
Thinking Outside the Pillbox - Medication Adherence as a Priority for Health Care Reform
}

\section{Citation}

Cutler, David M., and Wendy Everett. 2010. "Thinking Outside the Pillbox - Medication Adherence as a Priority for Health Care Reform." N Engl J Med 362 (17) (April 29): 1553-1555. doi:10.1056/nejmp1002305.

\section{Published Version}

doi:10.1056/NEJMp1002305

\section{Permanent link}

http://nrs.harvard.edu/urn-3:HUL.InstRepos:26640488

\section{Terms of Use}

This article was downloaded from Harvard University's DASH repository, and is made available under the terms and conditions applicable to Other Posted Material, as set forth at http:// nrs.harvard.edu/urn-3:HUL.InstRepos:dash.current.terms-of-use\#LAA

\section{Share Your Story}

The Harvard community has made this article openly available.

Please share how this access benefits you. Submit a story.

Accessibility 


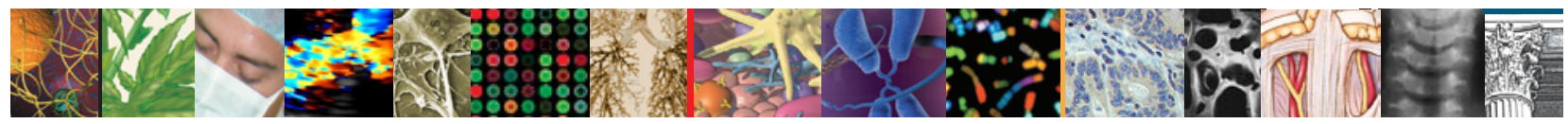 \\ The NEW ENGLAND JOURNAL of MEDICINE}

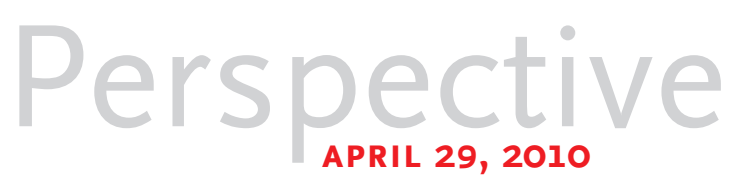

\section{Thinking Outside the Pillbox - Medication Adherence as a Priority for Health Care Reform}

David M. Cutler, Ph.D., and Wendy Everett, Sc.D.

\section{Door adherence to treatment regimens has long been recognized as a substantial roadblock to achieving better outcomes for patients. Data show that as many as half of all patients do not adhere}

faithfully to their prescriptionmedication regimens - and the result is more than $\$ 100$ billion spent each year on avoidable hospitalizations. ${ }^{1}$ Nonadherence to medication regimens also affects the quality and length of life; for example, it has been estimated that better adherence to antihypertensive treatment alone could prevent 89,000 premature deaths in the United States annually. ${ }^{2}$

What is less clear is why adherence to the 3.8 billion prescriptions written every year is so poor. Out-of-pocket costs for medication clearly affect adherence; people use more drugs when the prices of the drugs are lower. But even if drugs were free, nonadherence would persist: one recent study showed that even among patients who have health plans with no cost sharing for medications, rates of nonadherence were nearly $40 \% .^{3}$

Lack of coordination of care is another major factor. There is much more that could be done at the time a physician prescribes a medication to optimize and tailor regimens for individual patients. For patients with coexisting conditions who take multiple medications prescribed by multiple physicians, there is a vital need to reconcile the prescribed regimen with what a patient is actually taking and to understand why there is a difference between the two. But optimizing and reconciling medications require sub- stantial investments of time by a skilled health care practitioner, as well as electronic data sharing among practitioners - neither of which is widely available in today's model of health care delivery.

There are also numerous factors that affect adherence at the individual level, including lifestyle, psychological issues, health literacy, support systems, and side effects of medications. Indeed, patients' personal attributes probably have the strongest influence on adherence. Engaging and supporting patients in improving their adherence are critical to improving health outcomes. In today's system, however, there are neither the incentives nor the support systems to do so.

Taken together, these findings suggest that improved adherence will require changes in health care delivery, particularly in the area of primary care, along with 
Current Integrated Approaches to Promoting Adherence and Their Effects.

Community Care of North Carolina (CCNC), a loose affiliation of 14 physician networks serving Medicaid and uninsured patients, has launched the Pharmacy Home Project, a plan that pays participating physicians a monthly fee for coordination of care. Adherence is promoted through the use of case managers who are embedded throughout the networks and clinical pharmacists who serve multiple physician practices on a rotating basis and through the collection of data on patient medications from multiple sources including medical charts, claims records, and records of prescriptions filled to provide prescribers with complete and accurate data for use in reviewing medications. Under this program, CCNC has achieved a 5 to $7 \%$ increase in adherence rates.

Geisinger Health System, in Pennsylvania, has begun implementing multiple programs to address adherence. One approach is to collect patients' medication preferences through an electronic survey completed before a physician sees the patient. As part of Geisinger's medical home model, nurses actively follow up with patients to monitor medication use and address any questions or concerns the patient might have. The health system has also made changes to its own employee health benefits by reducing copayments and deductibles for medications for chronic conditions. Geisinger reports that it has achieved a 5 to $7 \%$ reduction in monthly costs.

At Group Health Cooperative, in Washington State and northern Idaho, the approach to adherence relies on nurse case managers who interview patients to assess whether they are managing their medical conditions and to increase patients' adherence to their medication regimens. Case managers also educate patients about their conditions, create action plans with patients, and refer patients to programs that help them find more affordable medications. The Group Health Cooperative reports that the results have included annual savings - representing avoided health care costs - of more than $\$ 476$ per participant.

continued investment in information-technology systems and new health plan designs that focus on achieving improved health outcomes. Fortunately, there are a number of real-world examples that teach important lessons about how to improve medication adherence. For instance, two wellknown integrated health care delivery systems, Geisinger Health System and Group Health Cooperative, have made adherence a priority and have begun to tackle the problem through multidimensional approaches. The Community Care of North Carolina program has a similar objective (see box). And studies point to improved adherence and outcomes among patients with particular conditions, such as HIV infection, AIDS, and heart failure. The success stories are there, though they are still scattered.

All these programs leverage information technology and patient-level data. They focus on understanding the patients' attributes and tailoring interventions to those attributes. In addition, they offer follow-up and patient support provided by health care professionals who are trained and empowered to work closely with patients to improve adherence.

We believe that there are four lessons to be learned from the successes in the field. First, measures for improving adherence must address financial barriers, especially the copayments that patients must make for medications. Given the growing evidence showing a strong link between reducing copayments for medications for chronic conditions and improving adherence, the movement by many large employers toward value-based insurance design (tailoring cost sharing to the value of the service provided) is an excellent first step. But more can be done. For example, patients could be given financial incentives or other rewards for appropriate adherence to medication regimens. Research shows that the more frequent the reward, the better; thus, smaller amounts provided regularly are likely to be more effective than bigger amounts provided sporadically.

Second, data and data infrastructure that support interventions to boost adherence need to be a high priority in the country's new investment in health information technology (HIT) and electronic health records. The guidelines promulgated by the Obama administration for "meaningful use" of HIT are promising. But the country's HIT strategy should not only recommend the incorporation of accurate medication data (e.g., medication histories and rates of filling and refilling of prescriptions) into electronic medical records but also encourage data sharing across care providers and care settings, including physicians' offices, hospitals, pharmacies, home health care agencies, and others.

Third, payment reform will be essential. Shifting from a fee-forservice model to payment systems that reward care providers for better patient outcomes and encourage coordination of care is critical to providing the incentives and investments that are required for improving adherence. Recent shifts to paying for medical homes and care transitions are trends that should support improved adherence. But to ensure that adherence actually improves, goals for medication adherence should be explicitly written into the performance measures for medical homes, accountable care 
organizations, and care transition teams. In the short run, efforts aimed at increasing adherence to medication regimens will require funds to be allocated up front. Over time, there should be savings. Thus, the structure of reimbursement must create an inducement for investment (typically by providers) that is financed by the groups that will save (usually insurers).

Finally, there needs to be greater use of proven screening and assessment tools to identify and target the patients who are at the greatest risk for nonadherence. Treatment guidelines for chronic conditions, for instance, should recommend screening for depression, which can be an indicator of poor adherence. In addition, assessment tools can broadly predict a patient's proclivity to adhere to treatment, ${ }^{4}$ which is valuable information for providers to use in encouraging adherence both at the point of prescribing and in follow-up contacts with patients.

Once the right patients are targeted, there is still a lot to learn about tailoring adherence interventions to individual patients. Although we know about many common features of adherence programs, it is more difficult to determine the best possible combination of such features for any given person. New investments in research, including efforts associated with the government's expanded program of comparative-effectiveness research, could dramatically enhance the evidence base for effective adherence interventions.

The bottom line is this: We've known for some time that improved adherence can lead to improvements in health outcomes and reductions in health care spending. What we haven't known is where to start. With the new federal health care reform law moving into implementation, the existing movements toward deployment of HIT, improved coordination of care, and payment reform together create a desire and an infrastructure for improving health outcomes through improved adherence. Now we just need to get moving.

Disclosure forms provided by the authors are available with the full text of this article at NEJM.org.

From Harvard University (D.M.C.) and the New England Healthcare Institute (W.E.) both in Cambridge, MA.

This article (10.1056/NEJMp1002305) was published on April 7, 2010, at NEJM.org.

1. Osterberg L, Blaschke T. Adherence to medication. N Engl J Med 2005;353:487-97.

2. Cutler DM, Long G, Berndt ER, et al. The value of antihypertensive drugs: a perspective on medical innovation. Health Aff (Millwood) 2007;26:97-110.

3. Doshi JA, Zhu J, Lee BY, Kimmel S, Volpp KG. Impact of a prescription copayment increase on lipid-lowering medication adherence in veterans. Circulation 2009;119:390-7. 4. Mosen DM, Schmittdiel J, Hibbard J, Sobel D, Remmers C, Bellows J. Is patient activation associated with outcomes of care for adults with chronic conditions? J Ambul Care Manage 2007;30:20-9.

Copyright $\odot 2010$ Massachusetts Medical Society.

\section{Specialist Physician Practices as Patient-Centered Medical Homes}

Lawrence P. Casalino, M.D., Ph.D., Diane R. Rittenhouse, M.D., M.P.H., Robin R. Gillies, Ph.D., and Stephen M. Shortell, Ph.D., M.P.H.

$\mathrm{D}$ uring the past few years, widespread support has emerged for the patient-centered medical home (PCMH) model of health care delivery. The PCMH combines traditional concepts of primary care (a personal physician providing first-contact, continuous, and comprehensive care) with newer responsibilities to systematically improve the health of the medical home's patient population (e.g., through the use of chronic disease registries, information technology, and new op- tions for communication between patients and the practice). The framework for the model was created by the American College of Physicians (ACP), the American Academy of Family Physicians (AAFP), the American Academy of Pediatrics (AAP), and the American Osteopathic Association $(\mathrm{AOA})^{1}$ and has been endorsed by the American Medical Association (AMA) and several medical specialty associations, including the American College of Cardiology, the American Col- lege of Chest Physicians, and the American Academy of Neurology. This model is a prominent component of the health care reform bill recently signed by President Barack Obama and is being tested in dozens of pilot projects around the country; it has been promoted by the Patient-Centered Primary Care Collaborative, a coalition of more than 500 large employers, consumer groups, health plans, labor unions, and physician and hospital organizations. 